Open Access

\title{
Digital Optical Biopsy of the Retina (Quantumpixelometria)
}

\section{Jorge Oscar Zarate}

Professor, Faculty of Medicine, University of Buenos Aires, Laboratory of Digital Pathology, Maimonides University, Buenos Aires, Argentina

\section{Article Info}

*Corresponding author:
Jorge Oscar Zarate
Professor
Faculty of Medicine
University of Buenos Aires
Laboratory of Digital Pathology
Maimonides University
Buenos Aires
Argentina
Email: zjorgeoscar@yahoo.com.ar

Received: May 31, 2016

Accepted: June 28, 2016

Published: July 5, 2016

Citation: Zarate JO. Digital Optical Biopsy of the Retina (Quantumpixelometria). Madridge J Ophthalmol. 2016; 1(1): 10-11.

doi: $10.18689 /$ mjop-1000104

Copyright: (c) 2016 The Author(s). This work is licensed under a Creative Commons Attribution 4.0 International License, which permits unrestricted use, distribution, and reproduction in any medium, provided the original work is properly cited.

Published by Madridge Publishers
"When it seems diminished the possibilities of new molecules to unravel the mysteries of life and death, a new physical design as sequential core of the dynamic structures arises: The Pixel"

The geometry of the pixels denotes a certain combination of eucldiana and twodimensional elliptical, especially with options $3 \mathrm{D}$ allowed in the construction scheme gemétrica Riemannian, and the stocks of subpixels (red, green and blue) dead pixels and stuck, expressing where color and resolution monitors have reached almost improbable geometric expressions, graphics cards such as the S3, NVIDIA, or ATI among others. giving the opportunity to overcome infinitely genome combination possibilities of identification, in this case with 16.8 million colors. (32 bits).

The QRS, the old fingerprint, facial detectors FBT face detection, bar codes, different forms of interferometry and spectrometric, have led to the possibility of using noninvasive methods of protein identity uncalculated limits or the DNA.

The pixelometrá new non-Euclidean geometry, to our knowledge, we advise sobe the pixel, as measurement converter, density, metric, shapes, etc.

The group of experts JPG (Joint Photographic Experts Group), have advanced significantly to the compression of images, both color and grayscale high quality) form, giving the fabulous figure of $16,000,000$ colors in the saves images.

The pixeloarquitectura that information across multiple cuts allows us to acquire eg is well built. An optical coherence tomography of retina, the structure of a cell or a protein, focal and morphologically ready.

In the world of pixels identified by images square, hexagonal, rectangular, round, dead, etc., ie no information propia. No morphology forget that the image (pixel), decoded, it is morphology.

Quantum computing is a computing paradigm different from classical computing. It is based on the use of qubits instead of bits, and gives rise to new logic gates that make possible new algorithms.

In the digital computing, a bit can take only two values: 0 or 1 . However, in quantum computing, involving the laws of quantum mechanics and the particle can be in coherent superposition: can be 0,1 and can be 0 and 1 at a time (a two orthogonal states subatomic particle). This allows you to perform several operations at once, depending on the number of qubits.

The number of qubits indicates the number of bits that can be in superposition. With conventional bits, if we had a record of three bits, there were eight possible values and the registry only could take one of those values. But if we have a vector three qubits, the particle can take eight different values simultaneously due to quantum superposition. 
Thus a three qubits vector allow a total of eight parallel operations. As expected, the number of operations is exponential with respect to the number of qubits.

Biological developments still exist in the device level. DNA is a stable means of information and advances in the synthesis and DNA sequencing have resulted in a reliable increase in digital storage media of high density.

However, the possibility of storing their own information, a unit, which is the pixel, makes it more accurate, dynamic and reliable. Quantum physics is the physics of the possibilities of change, management of unified fields of the four forces: gravity, electromagnetism and the strong and weak force of the atomic nucleus.

Einstein suggested in his theories, the existence of a field holding space-time transformations and mass - energy. This field is the pixel.Inthe photo show, can be seen digital secuentiation of isolated melanomas cells in retinal tissue infiltration, with in vivo detection technique based in sequencing images, obtained in our Digital Laboratory (Maimonides University).

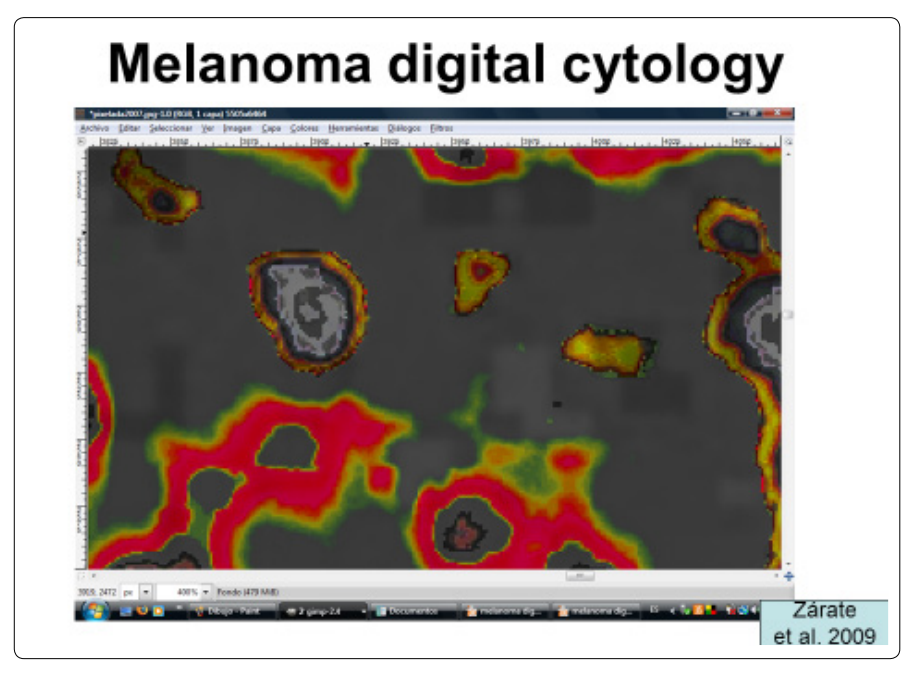

\section{References}

1. Zarate JO, Pelayes D, Singh A. Optical digital biopsy. A new method of tissue and cell identification with ophthalmic applications. Patología 2012; 50(3):179-181.

2. Zárate JO. Optical Digital Biopsy. Brush strokes and pixels in the wonderful Latinamerican iconography. Patología 2013; 51(3):206-9.

3. Zárate JO. Digital opticalbiopsy. Possible extension to no other ophthalmic tissue. Patología Rev Latinoam 2014; 52:246-247.

4. Zarate JO, The pixelometría. New non-Euclidiangeometry, biological importance. Patologia 2014 (Mex)

5. Zárate J O et al. Optical Digital Biopsy: Uveal Choroidal Melanoma: Case Report and Update of Technology. Open Science Journal of Clinical Medicine. 2015; 3(2): 59-63.

6. Zárate Jorge Oscar, Pelayes David, Folgar Martin, Lacarta Guillermo, Alvarado Miguel. Optical Digital Biopsy: Subcellular Identification and Update of Technology. Open Science Journal of Bioscience and Bioengineering. Vol. 2, No. 2, 2015, pp. 29-32.

7. Zárate $\mathrm{J} O$ et al. Optical Digital Biopsy: Uveal Choroidal Melanoma: Case Report and Update of Technology. Open Science Journal of Clinical Medicine. Vol. 3, No. 2, 2015, pp. 59-63.

8. Wojtkowski M, Bajraszewski T, Gorczynska I, et al.Ophthalmic imaging by spectral optical coherencetomography. Am J Ophthalmol 2004; 138: 412. 